\title{
Editoriạl
}

\section{Let's Take PORCC (Pork) Out of the Barrel}

\section{Louis Weinstein, MD}

As we enter the 21st century, medicine as a profession and we as professionals are in great distress. We have spent many years in training and sacrificed much to become a physician in order to care for patients. Medicine has changed the profession and the art of practice into an industry with a new alphabet soup terminology, including MSO, PPO, PHO, HMO, and 000 (just kidding). We are no longer called "physicians" but labeled as providers offering a service to clients (patients) who are equivalent to customers.

Among professionals, physicians are poorly organized and not used to fighting for what we know to be in the best interests of our patients. Physicians love rules and structure as can be demonstrated by our keen interest in protocols and our easy acceptance of clinical pathways. Knowing that we easily accept rules, the individuals who control the medical industry are using these attributes of physicians to dominate and keep our input to a minimum in the decision-making processes now going on in medicine. The health care conglomerates on Wall Street do not want interference from physicians because they believe we do not know what is "best" for the industry. The health care industry is one of the few major industries controlled by people who are not trained in production or have the skills to produce any of the product that they sell.

Physicians must accept much of the blame for the current state of affairs in medicine. Previously, we have focused on quality of care, extending longevity and producing new technology with little attention being given to cost. We must become more conscious of cost, control unnecessary testing, and utilize evidence-based medicine before adopting every new expensive technological development. We have to realize that medicine is a business, but a majority of the profits generated from health care must be returned to the system in order to benefit society. An example of how this is not occurring is demonstrated by the 1995 revenues of a single large health care conglomerate, which were 17.7 billion dollars with 1995 profits of 961 million dollars. The majority of these funds are removed from the system with the public receiving little future benefits from this vast money-making machine. The medical education system that is currently fighting to compete on an equal playing field with the medical industrial giants could survive for years on just 12 months of revenues generated by

Department of Obstetrics and Gynecology, Medical College of Ohio, Toledo, $\mathrm{OH}$.

Address correspondence and reprint requests to Louis Weinstein, MD, Department of Obstetrics and Gynecology, Medical College of Obio, Richard Ruppert Health Center, 3120 Glendale Avenue, Toledo, $\mathrm{OH} 43614-5809$. this corporation (17.7 billion dollars). These companies are reaping the benefits of our medical education system, our research developments, and the hard work of many health care providers with minimal return to the system that made most of this possible.

As physicians, we must take a leadership role in the business aspects of medicine. We have allowed control to fall to hospital administrators, insurance executives, and executive officers of health maintenance organizations. The growth rate of these individuals has exceeded that of most aggressive malignancies.

In the past, physicians volunteered to assist in the running of most hospitals. Now, administrators, with minimal training in actual health care delivery and no training in direct patient care, are telling us how to run our profession. They generate no revenue yet cost $25 \%$ of all hospital income.

I wish to suggest some solutions to solving the problem of excessive hospital administrators. First, the number of hospital administrators should never exceed the number of operating rooms in the individual hospital. The Chief of Staff should be an individual who is an advocate for the patients and the medical staff and not a voice for administration. The medical staff must become active in selecting the Chief of Staff and the hiring of all administrators. There should be direct contact between the hospital board and the medical staff. The administration offices should be placed on patient floors utilizing the same elevators and bathrooms as the patients they state they are so committed to serve. Administrators should be required to take call in the hospital several times per month, utilizing the same facilities as the on-call physicians and working similar hours. All administrators should have the pleasure of obtaining authorization for medical services for five patients per month.

We must make our colleagues, politicians, and patients demand that health maintenance organizations and managed care plans compete on the basis of quality of care, access to care, and responsiveness to patient needs and not solely on cost. Physicians must join together in a coalition that I shall call "PORCC"-Physicians Organized for Responsive Cost-Conscious Care. As a profession, we must take an active role in the health care system and be advocates for our patients. Is there any more valuable product available than good health? We have trained too hard, care too much, and have chosen the most noble of professions to give it away to those motivated by market share and monetary gain. If you love medicine as much as I do, speak up and take back the leadership for our profession. Let us take PORCC out of the barrel. 